\title{
Knowledge, Attitude, and Practices of Dental Surgeons in managing Child Patients
}

\author{
${ }^{1}$ Aisha Wali, ${ }^{2}$ Talha Mufeed Siddiqui, ${ }^{3}$ Rabia Khan, ${ }^{4}$ Kanza Batool
}

\begin{abstract}
The aim of the study was to evaluate the knowledge, attitude, and practices of dental surgeons in the city of Karachi providing treatment to pediatric patients. A cross-sectional study was conducted to evaluate the knowledge, attitude, and practices of dental surgeons in the city of Karachi providing treatment to pediatric patients. A cluster-sampling technique was used and 200 dental surgeons from six different dental institutions were selected. A self-constructed questionnaire was distributed to the dental surgeons that comprised 20 closed-ended questions. The data was entered and analyzed for frequency and percentages by using Statistical Package for the Social Sciences (SPSS) version 19. The results showed that $76(38 \%)$ dental surgeons took the responsibility of managing pediatric patient when given; $68(34 \%)$ dental surgeons allowed the parents in the clinic; $111(55.5 \%)$ dental surgeons are of the view that colorful and fun environment in dental clinic make the child at ease; $59(29.5 \%)$ always demonstrate the dental procedure to the child to eradicate imaginary fears; 94 (47.0\%) dental surgeons preferred the child to be treated in general anesthesia (GA) to avoid difficult behavior of the child; $135(67.5 \%)$ dental surgeons did not show syringe needle or any instrument to the child. All the members of dental profession must be aware of patient perceptions, preferences, and fear to meet patient's needs. Dental studies should include guidelines and techniques to train the upcoming dentists for excellent practice in pediatric dentistry.
\end{abstract}

Keywords: Attitude and practices, Behavioral techniques, Pediatric patients.

How to cite this article: Wali A, Siddiqui TM, Khan R, Batool K. Knowledge, Attitude, and Practices of Dental Surgeons in managing Child Patients. Int J Clin Pediatr Dent 2016;9(4):372-378.

Source of support: Nil

Conflict of interest: None

\footnotetext{
${ }^{1}$ Senior Lecturer, ${ }^{2}$ Associate Professor, ${ }^{3}$ Demostrator, ${ }^{4}$ House Surgeon

${ }^{1,2,4}$ Department of Operative Dentistry, Baqai Dental College Karachi, Sindh, Pakistan

${ }^{3}$ Department of Oral Biology, Baqai Dental College, Karachi Sindh, Pakistan

Corresponding Author: Aisha Wali, Senior Lecturer, Department of Operative Dentistry, Baqai Dental College, Karachi, Sindh Pakistan, Phone: +00922134410293, e-mail: aishawali@ hotmail.com
}

\section{INTRODUCTION}

Dental surgeons are expected to diagnose and manage effectively childhood dental diseases that are within the knowledge and skills acquired during dental education. ${ }^{1}$ Safe and effective treatment provided often requires modifying the child's behavior. ${ }^{2}$ Pediatric dentistry is considered to be the most needed and yet neglected area of all the services performed by the dental surgeons. ${ }^{3}$ The auxiliary staff, as well as the clinical team, should be welcoming and friendly. ${ }^{4}$ Communication with the children should be age-specific, and the dental team should develop a specialized vocabulary. ${ }^{5}$ A child's future attitude toward dentistry may be determined by a series of successful experiences in a pleasant dental environment. Dental surgeons should be encouraged to increase and update their clinical skills and knowledge in behavior guidance techniques by reading dental literature, observing video presentations, or attending continuing education programs. ${ }^{6}$ The establishment of good relationship between dentist and the child has been shown to increase the success of treatment in terms of the child's cooperation during the treatment or advice for prevention. ${ }^{7}$ Parents exert a significant influence on their child's behavior, especially if they had previous negative dental experiences. ${ }^{8-10}$ An anxious or fearful parent may affect the child's behavior negatively. ${ }^{8,9,11}$ Educating the parent before the child's first appointment is important, and effective communication with more demanding parents represents an opportunity for the dental surgeon to carefully review behavior and treatment options and together decide what is in the child's best interests. ${ }^{12}$ Dental surgeons have the same opinion that good communication is important amongst the dentist, patient, and parent in building trust and confidence. ${ }^{12,13}$ Communication skills of the dental surgeons play an important role in behavior guidance and the health professionals may be inattentive to communication style, but parents/patients are very attentive to it. ${ }^{14}$ Dental surgeons behaviors reported to correlate with low parent satisfaction include rushing through appointments, not taking time to explain the procedures, barring parents from the examination room, and generally being impatient. ${ }^{15}$ Dental surgeons behavior of vocalizing, directing, empathizing, persuading, giving the patient a feeling of control, and operant conditioning have 
been reported as efficacious responses to uncooperative patient behaviors. ${ }^{16}$ The most common emotional upsets seen during dental treatment are anxiety and fear, which might originate from a previous traumatic experience in the dental office or during hospitalization for other reasons. ${ }^{17}$ Dental anxiety and fear of dental treatment in children are considered to be the main reason for management problems and avoidance of dental care. These problems sometimes require replacement of conventional treatment with more complicated alternatives, such as sedation or general anesthesia (GA) ${ }^{18}$ Children who have positive interactions with their dentist will be more likely to visit the dentist and will have better dental health. ${ }^{19}$ Moreover, pediatric dentistry demands the use of diagnostic aids as well as correct interpretation of findings both in emergency and in routine problems. ${ }^{20}$ Various barriers including developmental delay, physical/ mental disability, and acute or chronic disease all are potential reasons for noncompliance and may hinder the achievement of a successful outcome. To alleviate these barriers, the dental surgeon should become a teacher and the methods should include active listening and observation of child's body language. ${ }^{21}$ Shortcoming of most of the dental surgeons when treating children is their lack of knowledge, clinical skill, or attention to the vital performance of providing and assuring profound local anesthesia. Most of the dental surgeons felt uncomfortable with their clinical skills and avoid giving children local anesthesia. For this vision to become reality, many more dental professionals will need to be aware of and skilled in the communication management methods advocated by the American Academy of Pediatric Dentistry. ${ }^{22}$

Therefore, the aim of the study was to evaluate the knowledge, attitude, and practices of dental surgeons in the city of Karachi providing treatment to pediatric patients.

\section{MATERIALS AND METHODS}

\section{Study Design}

A cross-sectional study was conducted in May 2014 to February 2015 to evaluate the knowledge, attitude, and practices of dental surgeons in the city of Karachi providing treatment to pediatric patients.

\section{Ethical Approval}

The study was approved by the Ethical Committee, Baqai Medical University.

\section{Sampling Technique}

A cluster-sampling technique was used and 200 dental surgeons from six different dental institutions were selected. A self-constructed questionnaire (Fig. 1) was distributed to the dental surgeons that comprised 20 closed-ended questions, including the parental influence, communication with the child, decorations and accouterments depicting definite settings, importance of demonstrating a child about treatment, sedative procedures, and various barriers that hinder the dental treatment.

\section{Inclusion Criteria}

Dental surgeons with the clinical experience of 3 years and above currently working in dental institutes of Karachi.

\section{Exclusion Criteria}

Clinical experience below 3 years. Currently not working in a dental institution.

\section{Statistical Analysis}

The data was entered and analyzed for frequency and percentages by using Statistical Package for the Social Sciences (SPSS) version 19.0.

\section{RESULTS}

The present study comprised 200 dental surgeons of experience level 3 years and above. Table 1 shows the descriptive analysis of the knowledge, attitude, and practices of dental surgeons providing treatment to pediatric patient. Results showed that 76 (38\%) dental surgeons took the responsibility of managing pediatric patient when given; $68(34 \%)$ dental surgeons allowed the parents in the clinic as a spectator to encourage and assure the child to work in a satisfactory manner; 111 (55.5\%) dental surgeons are of the view that colorful and fun environment in dental clinic makes the child at ease, while 67 (33.5\%) dental surgeons think that having a handy music system/video will provide comfort to frightened children; 59 (29.5\%) always demonstrate the dental procedure to the child to eradicate imaginary fears; 102 (51\%) preferred not to inform the child that the dental procedure could involve pain. Table 2 shows behavior attributes of dentists toward pediatric patients; 109 (54.5\%) dental surgeons preferred to treat the child without anesthesia to prevent from unpredictable behavior of child; 94 (47.0\%) dental surgeons preferred the child to be treated in GA to avoid difficult behavior of the child; 135 (67.5\%) dental surgeons did not show syringe needle or any instrument to the child as a good policy to carry out the treatment; 105 (52.5\%) praised the good behavior of child to acknowledge exemplary conduct in a child. Table 3 shows sedation techniques used by dental surgeons on pediatric patient. Of dental surgeons, 76 (38.0\%) occasionally allow the parents to take part in treatment verbally to approach the psychological 
1. Do you take the responsibility of working on child when needed?

- Always

- Often

- Sometimes

- Never

2. Do you allow the parent in the clinic while the dental treatment is being performed?

- Always

- Often

- Sometimes

- Never

3. Do you think keeping office decorations and accoutrements attractive to children and play any role in treatment?

- Always

- Often

- Sometimes

- Never

4. Do you think playing video or music to direct the child's focus away from the dental treatment?

- Always

- Often

- Sometimes

- Never

5. Do you demonstrate the procedure to child patient what is to be done?

- Always

- Often

- Sometimes

- Never

6. Do you aware the child that dentistry may involve pain?

- Always

- Often

- Sometimes

- Never

7. Is it acceptable for you to treat the child without anesthesia?

- Always

- Often

- Sometimes

- Never

8. Do you prefer the child to be treated under general anesthesia in a hospital to avoid awareness of the dental experience?

- Always

- Often

- Sometimes

- Never

9. Do you use nitrous oxide inhalation or drugs to sedate the child?

- Always

- Often

- Sometimes

- Never

10. Do you show the needle of a syringe and dental instruments to a child?

- Always

- Often

- Sometimes

- Never
11. Do you use sentences to encourage the child not to be a coward?

- Always

- Often

- Sometimes

- Never

12. Do you allow the parent to talk to his/her child while the child receives dental treatment?

- Always

- Often

- Sometimes

- Never

13. Do you ever modify your voice volume, tone, or pace to direct the child's behavior?

- Always

- Often

- Sometimes

- Never

14. Do you allow the child to speak since he/she may interfere with the treatment?

- Always

- Often

- Sometimes

- Never

15. Do you allow the patient to stop the treatment when discomfort is felt?

- Always

- Often

- Sometimes

- Never

16. If a child is quiet during the treatment, is it acceptable for you not to speak?

- Always

- Often

- Sometimes

- Never

17. Do you place your hand over the mouth of a hysterical or out-of-control child to achieve silence?

- Always

- Often

- Sometimes

- Never

18. Do you immobilize the child by yourself, the dental staff, and/or a parent when needed?

- Always

- Often

- Sometimes

- Never

19. Do you praise the child when he/she does something is asked to do?

- Always

- Often

- Sometimes

- Never

20. Do you promise the child any complimentary gift if he/she cooperates with you?

- Always

- Often

- Sometimes

- Never

Fig. 1: Questionnaire 
Knowledge, Attitude, and Practices of Dental Surgeons in managing Child Patients

Table 1: Descriptive analysis of the knowledge, attitude, and practices of dental surgeons providing treatment to pediatric patients

\begin{tabular}{lll}
\hline Questionnaire & Mean & $\begin{array}{l}\text { Standard } \\
\text { deviation }\end{array}$ \\
\hline Responsibility of managing child patient & 2.09 & 0.939 \\
Allow parent in clinic & 2.17 & 1.020 \\
Keep office decor & 1.65 & 0.838 \\
Talking and playing video or music to & 2.24 & 1.085 \\
distract the child & & \\
Demonstrate procedure & 2.32 & 1.078 \\
Aware child of pain & 3.14 & 1.059 \\
Treat without anesthesia & 3.34 & 0.841 \\
Prefer GA for treatment & 3.34 & 0.816 \\
Nitrous oxide inhalation to sedate & 3.06 & 0.671 \\
Don't show needle of syringe & 3.46 & 0.907 \\
Encourage child not to be coward & 1.85 & 1.060 \\
Allow parent to interrupt & 2.46 & 1.031 \\
Modify voice, tone to direct child behavior & 2.22 & 1.018 \\
Allow child to speak & 2.48 & 0.997 \\
Patient to stop treatment on discomfort & 1.93 & 1.010 \\
Stop hysterical child by hand on mouth & 3.49 & 0.845 \\
Immobilize the child & 2.91 & 0.920 \\
Praise the child & 1.68 & 0.934 \\
Give complimentary gifts & 2.46 & 2.288 \\
\hline
\end{tabular}

Table 3: Sedation techniques used by dental surgeons on pediatric patient

\begin{tabular}{|c|c|c|c|c|}
\hline \multirow[b]{2}{*}{ Questionnaire } & \multicolumn{4}{|c|}{ Frequency and percentages } \\
\hline & Always & Often & Sometimes & Never \\
\hline $\begin{array}{l}\text { Who aware } \\
\text { the child about } \\
\text { involvement } \\
\text { of pain }\end{array}$ & $25(12.5 \%)$ & $25(12.5 \%)$ & $48(24 \%)$ & $102(51 \%)$ \\
\hline $\begin{array}{l}\text { Who treat the } \\
\text { child without } \\
\text { anesthesia }\end{array}$ & $7(3.5 \%)$ & $27(13.5 \%)$ & $57(28.5 \%)$ & $109(54.5 \%)$ \\
\hline $\begin{array}{l}\text { Who prefer } \\
\text { the child to be } \\
\text { treated in GA }\end{array}$ & $9(4.5 \%)$ & $34(17 \%)$ & $94(47 \%)$ & $63(31.5 \%)$ \\
\hline $\begin{array}{l}\text { Who use } \\
\text { nitrous oxide } \\
\text { inhalation to } \\
\text { sedate the child }\end{array}$ & $14(7.0 \%)$ & $15(7.5 \%)$ & $36(18 \%)$ & $140(70 \%)$ \\
\hline $\begin{array}{l}\text { Who do not } \\
\text { show needle } \\
\text { of syringe/ } \\
\text { instrument to } \\
\text { child }\end{array}$ & $14(7.0 \%)$ & $15(7.5 \%)$ & $36(18 \%)$ & $135(67.5 \%)$ \\
\hline
\end{tabular}

management of the patient; 61 (30.5\%) tended to modify their voice, tone to direct child's behavior; 80 (40\%) gave the child an opportunity to participate in the procedures; $94(47.0 \%)$ of dental surgeons deferred the treatment when discomfort is felt; 69 (34.5\%) dental surgeons chose not to engage the child in a conversation if he is not willing or showing interest; 136 (68\%) dental surgeons never placed their hand on the mouth of a screaming spoiled child; 90 (45\%) dental surgeons immobilize the child by their self and avoid any auxiliary help; $116(58 \%)$ dentists praise
Table 2: Behavior attributes of dentists toward pediatric patients

\begin{tabular}{|c|c|c|c|c|}
\hline \multirow[b]{2}{*}{ Questionnaire } & \multicolumn{4}{|c|}{ Frequency/percentages } \\
\hline & Always & Often & Sometimes & Never \\
\hline $\begin{array}{l}\text { Dental surgeons } \\
\text { that manage } \\
\text { pediatric patients }\end{array}$ & $73(36.5 \%)$ & $44(22 \%)$ & $76(38 \%)$ & $7(3.5 \%)$ \\
\hline $\begin{array}{l}\text { Dental surgeons } \\
\text { that allow parents } \\
\text { in dental clinic }\end{array}$ & $68(34 \%)$ & $50(25 \%)$ & $61(30.5 \%)$ & $21(10.5 \%)$ \\
\hline $\begin{array}{l}\text { Dental surgeons } \\
\text { keep off decor } \\
\text { attractive }\end{array}$ & $111(55.5 \%)$ & $56(28 \%$ & $26(13 \%)$ & $7(3.5 \%)$ \\
\hline $\begin{array}{l}\text { Talking and playing } \\
\text { video or music to } \\
\text { distract the child }\end{array}$ & $67(33.5 \%)$ & $50(25 \%$ & $51(25.5 \%)$ & $32(16 \%)$ \\
\hline $\begin{array}{l}\text { Dental surgeons } \\
\text { who demonstrate } \\
\text { the procedure to } \\
\text { child }\end{array}$ & $59(29.5 \%)$ & $54(27 \%$ & $52(26 \%)$ & $35(17.5 \%)$ \\
\hline $\begin{array}{l}\text { Dental surgeons } \\
\text { who encourages } \\
\text { child not to be } \\
\text { coward }\end{array}$ & $105(52.5 \%)$ & $44(22 \%$ & $27(13.5 \%)$ & $24(12 \%)$ \\
\hline
\end{tabular}

Table 4: Different treatment modalities by dental surgeons

\begin{tabular}{|c|c|c|c|c|}
\hline \multirow[b]{2}{*}{ Questionnaire } & \multicolumn{4}{|c|}{ Frequency and percentages } \\
\hline & Always & Often & Sometimes & Never \\
\hline $\begin{array}{l}\text { Who modify their } \\
\text { tone to direct } \\
\text { child's behavior }\end{array}$ & $61(30.5 \%)$ & $59(29.5 \%)$ & $55(27.5 \%)$ & $25(12.5 \%)$ \\
\hline $\begin{array}{l}\text { Who allow child } \\
\text { to speak during } \\
\text { treatment }\end{array}$ & $44(22 \%)$ & $46(23 \%)$ & $80(40 \%)$ & $30(15 \%)$ \\
\hline $\begin{array}{l}\text { Who stop } \\
\text { treatment when } \\
\text { discomfort is felt }\end{array}$ & $94(47.0 \%)$ & $41(20.5 \%)$ & $50(25 \%)$ & $15(7.5 \%)$ \\
\hline $\begin{array}{l}\text { Who do not } \\
\text { speak if child } \\
\text { is quiet }\end{array}$ & $42(21 \%)$ & $43(21.5 \%)$ & $69(34.5 \%)$ & $46(23 \%)$ \\
\hline $\begin{array}{l}\text { Who place hand- } \\
\text { over-mouth of } \\
\text { hysterical child }\end{array}$ & $7(3.5 \%)$ & $25(12.5 \%)$ & $32(16 \%)$ & $136(68 \%)$ \\
\hline $\begin{array}{l}\text { Who immobilize } \\
\text { the child by } \\
\text { themselves }\end{array}$ & $20(10 \%)$ & $34(17 \%)$ & $90(45 \%)$ & $56(28 \%)$ \\
\hline $\begin{array}{l}\text { Who praise child } \\
\text { when obeys } \\
\text { command }\end{array}$ & $116(58 \%)$ & $45(22 \%)$ & $26(13 \%)$ & $13(6.5 \%)$ \\
\hline $\begin{array}{l}\text { Who promise } \\
\text { complimentary } \\
\text { gifts }\end{array}$ & $58(29.0 \%)$ & $52(26 \%)$ & $57(28.5 \%)$ & $32(16 \%)$ \\
\hline
\end{tabular}

the child if he obeys a command in a determined way; $58(29 \%)$ dental surgeons promised to gift or reward a child to attain his maximum cooperation. Table 4 shows treatment modalities by different dental surgeons.

\section{DISCUSSION}

Results showed that 76 (38\%) of the dental surgeons took the responsibility of managing pediatric patients in 
dental clinics. The present survey done was one of the first kind to assess the behavior and attitudes of dental surgeons in Pakistan toward managing and treating pediatric patients. The findings from this survey that $38 \%$ of the dental surgeons provide treatment to children is not encouraging. Dental surgeons may simply be reluctant to see children so young because they perceive them to be difficult to examine. Further, they may not know what to do if, during the examination, it is discovered that the child will require further treatment. Educational programs should be planned for dental surgeons to improve their knowledge and skills in providing treatment to children. ${ }^{22}$ A survey done in Saudi Arabia reported that $85 \%$ of the dental surgeons treat children which is encouraging. ${ }^{23}$ Another study conducted by Seale and Casamassimo $^{24}$ reported that more than $90 \%$ of dental surgeons provide treatment to children younger than 4 years of age.

Pain management during dental procedures is essential for successful behavior guidance and enhancing positive dental attitudes for future appointments. Listening to the child and observing their behavior at first sign of distress would help in diagnosing the situation and facilitate proper behavior guidance techniques. ${ }^{25}$ Children perceive and react to painful stimuli differently from each other and under the age of 4 years are more sensitive to painful stimuli and are not able to communicate as well as older children and teens. ${ }^{21,26}$ Observing behavior and listening to children during treatment are essential in any evaluation of pain. Facial expressions, crying, complaining, and body movement are important diagnostic criteria. ${ }^{25,27-30}$ The present study reported that $25(12.5 \%)$ dental surgeons developed trust and explained the child about the nature of pain perception during dental procedures.

Parental accompaniment can significantly affect the atmosphere surrounding the dental visit and dental treatment and may sometimes enhance and sometimes hinder the progress of the child's treatment. ${ }^{7}$ The present study results showed that $68(34 \%)$ of the dental surgeons allowed parents in dental clinic. Levy and Domoto ${ }^{31}$ reported that $88 \%$ of dental surgeons and auxiliary staff allowed parents in the dental clinics. A survey done by the Association of Pedodontic Diplomats, ${ }^{32}$ nearly $90 \%$ of the dental surgeons allowed parents in the dental clinic. Another study ${ }^{33}$ reported that $35 \%$ of general dentists and $87 \%$ of pediatric dental surgeons allowed parents in the operatory.

Behavior guidance is a clinical art form and a skill built on a foundation of science with the goals to establish communication, alleviate fear and anxiety, deliver quality dental care, build a trusting relationship between dentist, child, and parent, promote the child's positive attitude to dental health. ${ }^{2}$ The most popular technique for managing children was tell-show-do and was reported by 213(93\%) dental surgeons as their most commonly used behavioral management strategy followed by $149(69 \%)$ reported voice control. The technique dentists were least comfortable with was hand-over-mouth; 7(3\%) dental surgeons reported feeling uncomfortable with hand-over mouth techniques, followed by $5(2 \%)$ with the papoose board. ${ }^{34-36}$ The present study results reported that $67(33.5 \%)$ of the dental surgeons used distraction technique followed by $61(30.5 \%)$ used voice control technique, 59(29.5\%) tellshow-do technique, 20(10\%) used papoose board, and $7(3.5 \%)$ used hand-over-mouth technique.

Dental surgeons make every effort to reduce or eliminate pain and anxiety experienced by children, but also to improve patient manageability and satisfaction. ${ }^{37}$ Klassen et $\mathrm{al}^{38}$ considered whether music could help control pediatric pain and anxiety. Filcheck et $\mathrm{al}^{39}$ found no differences in disruptive behaviors between music therapy and placebo overall, or by level of disruptiveness, there was a significant difference among the uncooperative children with respect to disruptive behaviors, crying and complaining, and physical restraint required. The present study reported that $67(33.5 \%)$ dental surgeons play music/video to distract the child's focus away from dental treatment.

Most children can be managed effectively using the techniques outlined in basic behavior guidance and these techniques should form the foundation for all of the management activities provided by the dental surgeon. The advanced behavior guidance techniques commonly used and taught in advanced pediatric dental training programs include protective stabilization, sedation, and GA. ${ }^{18}$ The sedation of children is different from the sedation of adults; sedation in children often is administered to control behavior to allow the safe completion of the dental procedure. A child's ability to control his or her own behavior to cooperate for a procedure depends both on his or her chronologic and developmental age. ${ }^{40}$

Nitrous oxide $\left(\mathrm{N}_{2} \mathrm{O}\right)$ is an attractive agent for pediatric procedural sedation because it provides rapid onset and offset of sedation. Most research has used 50\% $\mathrm{N}_{2} \mathrm{O}$, and there have been concerns regarding the variability of the sedation provided. ${ }^{41,42}$ A study done by Sarah et al reported that only $12(6 \%)$ of the dental surgeons preferred to use nitrous oxide as a behavorial management technique. ${ }^{43}$ Another study results reported that 159 (73\%) of the dental surgeons were totally comfortable with nitrous oxide sedation technique. ${ }^{7}$ The present study results showed that $14(7 \%)$ dental surgeons preferred to use nitrous oxide to sedate children.

Despite the risk of adverse events of GA, dental treatment performed in a hospital is generally considered 
safe. ${ }^{44}$ Pediatric dentists reported a favorable attitude toward dental treatment under GA, and many reported an increasing interest in utilizing this modality more frequently in their dental practices. ${ }^{45}$ Comprehensive dental care under GA is often more efficient and cost effective than repeated dental visits for restorative care utilizing other sedation methods. ${ }^{46}$ Dental restorations performed under GA, especially for the treatment of early childhood caries, are reported to have greater quality and durability than restorations placed under conscious sedation. ${ }^{47,48}$ Kain et $\mathrm{a}^{49}$ showed greater observed compliance during anesthetic induction. A study done by Manal et al reported that more than $50 \%$ of the general dentists and $60 \%$ of the pediatric dental surgeons reported the use of GA. ${ }^{50}$ In the survey by McKnight-Hanes et al, ${ }^{35} 60 \%$ of the pediatric dentists used GA in oral rehabilitation. It is likely that the differences are due to the fact that more than $60 \%$ of the dental surgeons were working in hospitals where facilities were usually provided for the utilization of GA. A study done by Crossley and Joshi ${ }^{7}$ reported that $98(45 \%)$ dental surgeons performed treatment under GA. The present study results showed that $9(4.5 \%)$ of the dental surgeons preferred the child to be treated in GA. Klingberg and Broberg ${ }^{51}$ reported that children and adolescents were expected to experience mild fear and anxiety during their dental treatment. Fear may be observed in children, adults, and the elderly, and it is suggested that young children and females are more likely to suffer from needle phobia. ${ }^{52}$ The present study results showed that $14(7 \%)$ of the dental surgeons showed needle to children during treatment.

\section{CONCLUSION}

All the members of dental profession must be aware of patients' perceptions, preferences, and fear to meet patient's needs. Dental studies should include guidelines and techniques to train the upcoming dentists for excellent practice in pediatric dentistry.

\section{REFERENCES}

1. Enrique B, Amir F, Riley J. Predoctoral and postdoctoral students' perspectives about pediatric dental behavior guidance. J Dent Educ 2011 May;75(5):616-625.

2. American academy of pediatric dentistry. Guideline on behavior guidance for the pediatric dental patient. Reference Manual. Pediatr Dent 2011;36(6):179-191.

3. Finn SB. Clinical pedodontics. 4th ed. Philadelphia: WB Saunders Company, 1998.

4. Gupta A, Marya CM, Bhatia HP, Dahiya V. Behaviour management of an anxious child. Stomatologija. Baltic Dent Maxillofac J 2014;16(1):3-6.

5. Fayle S, Crawford PJM. Making dental treatment acceptable to children. Dent Profile 1997:18-22.
6. Sheller B. Challenges of managing child behavior in the 21st century dental setting. Pediatr Dent 2004 Mar-Apr;26(2): 111-113.

7. Crossley M, Joshi G. An investigation of paediatric dentists' attitudes towards parental accompaniment and behavioural management techniques in the UK. Br Dent J 2002 May;192(9):517-521.

8. Versloot J, Craig KD. The communication of pain in paediatric dentistry. Eur Arch Paediatr Dent 2009 Jun;10(2);61-66.

9. Klingberg G, Berggren U. Dental problem behaviors in children of parents with severe dental fear. Swed Dent J 1992;16(1-2): 27-32, 39 .

10. Baier K, Milgrom P, Russell S, Mancl L, Yoshida T. Children's fear and behavior in private pediatric dentistry practices. Pediatr Dent 2004 Jul-Aug;26(4):316-321.

11. Long $\mathrm{N}$. The changing nature of parenting in America. Pediatr Dent 2004 Mar-Apr;26(2):121-124.

12. Feigal RJ. Guiding and managing the child dental patient: a fresh look at old pedagogy. J Dent Educ 2001 Dec;65(12): 1369-1377.

13. Freeman R. Communicating with children and parents: recommendations for a child-parent-centred approach for paediatric dentistry. Eur Arch Paediatr Dent 2008 Feb;9(1):16-22.

14. American Academy of Pediatrics, American Academy of Pediatric Dentistry. Guideline for monitoring and management of pediatric patients during and after sedation for diagnostic and therapeutic procedures. Pediatr Dent 2011;33(Special Issue):185-201.

15. American Academy of Pediatric Dentistry. Guideline on use of anesthesia personnel in the administration of office-based deep sedation/general anesthesia to the pediatric dental patient. Pediatr Dent 2011;33(Special Issue):202-204.

16. American Academy of Pediatric Dentistry. Proceedings of the consensus conference: behavior management for the pediatric dental patient. Chicago (IL): American Academy of Pediatric Dentistry; 1989.

17. Adair SM, Schafer TE, Rockman RA, Waller JL. Survey of behavior management teaching in predoctoral pediatric dentistry programs. Pediatr Dent 2004 Mar-Apr:26(2):143-150.

18. Adair SM, Rockman RA, Schafer TE, Waller JL. Survey of behavior management teaching in pediatric dentistry advanced education programs. Pediatr Dent 2004 MarApr:26(2):151-158.

19. Adair SM, Waller JL, Schafer TE, Rockman RA. A survey of members of the American Academy of Pediatric Dentistry on their use of behavior management techniques. Pediatr Dent 2004 Mar-Apr:26(2):159-166.

20. Pinkham JR. Patient management. In: Pinkham JR, Casamassimo PS, Fields HW Jr, McTigue DJ, Nowak AJ, editors. Pediatric dentistry - infancy through adolescence. 4 th ed. St Louis, MO: Elsevier-Saunders Co; 2005. p. 394-413.

21. Klingberg G. Dental anxiety and behaviour management problems in paediatric dentistry: a review of background factors and diagnostics. Eur Arch Paediatr Dent 2007 Feb;8(4): 11-15.

22. Cotton KT, Seale NS, Kanellis MJ, Damiano PC, BidautRussell M, McWhorter AG. Are general dentists' practice patterns and attitudes about treating Medicaid-enrolled preschool age children related to dental school training? Am Acad Pediatr Dent 2001 Jan-Feb;23(1):51-55.

23. Halawany HS, Al-Fadda SAA, Al-Saeed BHK. The attitude of private dental practitioners towards treatment and 
management of children in Riyadh, Saudi Arabia. J Pak Dental Assoc 2011;20(4):245-249.

24. Seale NS, Casamassimo PS. Access to dental care for children in the United States: a survey of general practitioners. J Am Dent Assoc 2003 Dec;134(2):1630-1640.

25. Nutter DP. Good clinical pain practice for pediatric procedure pain: neurobiologic considerations. J Calif Dent Assoc 2009;37(10):705-710.

26. Versloot J, Veerkamp JS, Hoogstraten J. Children's selfreported pain at the dentist. Pain 2008 Jul;137(2):389-394.

27. Nutter DP. Good clinical pain practice for pediatric procedure pain: iatrogenic considerations. J Calif Dent Assoc 2009;37(10):713-718.

28. Nutter DP. Good clinical pain practice for pediatric procedure pain: target considerations. J Calif Dent Assoc 2009;37(10): 719-722.

29. Nakai Y, Milgrom P, Mancl L, Coldwell SE, Domoto PK, Ramsay DS. Effectiveness of local anesthesia in pediatric dental practice. J Am Dent Assoc 2000 Dec;131(12):1699-1705.

30. American Academy of Pediatric Dentistry. Use of local anesthesia for pediatric dental patients. Pediatr Dent 2010; 32(Special Issue):141-147.

31. Levy RL, Domolo PK. Current techniques for behavior management: a survey. Pediatr Dent 1979 Sep;1(3):160-164.

32. Association of Pedodontic Diplomates. Techniques for behavior management a survey. ASDC J Dent Child 1972; 39(5):368-372.

33. Olsen JS, Kuster CG, Dubois LM. Behavior management of the child dental patient by general dentists in Nebraska: attitudes and practices. Gen Dent 1989;37(4):324-325.

34. Lawrence SM, McTigue DJ, Wilson S, Odom JG, Waggoner WF, Fields HW. Parental attitudes toward behaviour management techniques used in paediatric dentistry. Pediatr Dent 1991 May-Jun;13(3):151-155.

35. McKnight-Hanes C, Myers DR, Dushku JC, Davis HC. The use of behavior management techniques by dentists across practitioner type, age, and geographic region. Pediatr Dent 1993 Jul-Aug:15(4):267-271.

36. Murphy MG, Fields HW Jr, Machen JB. Parental acceptance paediatric dentistry behaviour management techniques. Pediatr Dent 1984 Oct;6(4):193-198.

37. Tanja B. Music therapy may reduce pain and anxiety in children undergoing medical and dental procedures. J Evid Based Dent Prac 2009 Dec;9(4):213-214.

38. Klassen JA, Liang Y, Tjosvold L, Klassen TP, Hartling L. Music for pain and anxiety in children undergoing medical procedures: a systematic review of randomized controlled trials. Ambul Pediatr 2008 Mar-Apr;8(2):117-128.
39. Filcheck HA, Allen KD, Ogren H, Darby JB, Holstein B, Hupp S. The use of choice-based distraction to decrease the distress of children at the dentist. Child Fam Behav Ther 2004 Jan;26(4):59-68.

40. Cunha RF, Delbem ACB, Percinoto C, Melhado FL. Behavioral evaluation during dental care in children ages 0 to 3 years. J Dent Child 2003 May-Aug;70(2):100-103.

41. Krauss B. Continuous-flow nitrous oxide: searching for the ideal procedural anxiolytic for toddlers. Ann Emerg Med 2001 Jan;37(1):61-62.

42. Krauss B, Green SM. Procedural sedation and analgesia in children. Lancet 2006 Mar;367(9512):766-780.

43. Sarah A, Fatemah A. Parents and dentists attitude toward the use of nitrous oxide sedation as a behavioral management technique during pediatric dental care in Kuwait. Elective Project Study Course No. 703. Department of Surgical Sciences, Kuwait University; 2013.

44. Lee JY, Roberts MW. Mortality risks associated with pediatric dental care using general anesthesia in a hospital setting. J Clin Pediatr Dent 2003 Summer;27(4):381-383.

45. Adair SM, Waller JL, Schafer TE, Rockman RA. A survey of members of the American Academy of Pediatric Dentistry on their use of behavior management techniques. Pediatr Dent 2004 Mar-Apr;26(2):159-166.

46. Lee JY, Vann WF, Roberts MW. A cost analysis of treating pediatric dental patients using general anesthesia vs conscious sedation. Pediatr Dent 2000;22(1):27-32.

47. Eidelman E, Faibis S, Peretz B. A comparison of restorations for children with early childhood caries treated under general anesthesia or conscious sedation. Pediatr Dent 2000 Jan-Feb;22(1):33-37.

48. Al-Eheideb AA, Herman NG. Outcomes of dental procedures performed on children under general anesthesia. J Clin Pediatr Dent 2003 Winter;27(2):181-183.

49. Kain ZN, Wang SM, Mayes LC, Krivutza DM, Teague BA. Sensory stimuli and anxiety in children undergoing surgery: a randomized, controlled trial. Anesth Analg 2001;92(4): 897-903.

50. Abushal MS, Adenubi JO. The use of behavior management techniques by dentists in Saudi Arabia: a survey. Saudi Dent J 2000;12(3):129-134.

51. Klingberg G, Broberg AG. Dental fear/anxiety and dental behaviour management problems in children and adolescents: a review of prevalence and concomitant psychological factors. Int J Paediatr Dent 2007 Nov;17(6):391-406.

52. Hamilton JG. Needle phobia - a neglected diagnosis. J Fam Pract 1995 Aug;41(2):169-175. 